\title{
55 YEARS OF THE JOURNAL MiTOM
}

Translated from Metallovedenie i Termicheskaya Obrabotka Metallov, No. 7, p. 3, July, 2010.

Five years ago our journal celebrated its 50 th year. The results of its activity were given in two issues, i.e. Nos. 7 and 8 (2005). The history of the creation of the journal was related in No. 7, and theoretical and practical problems of metallurgy and heat treatment, elucidated in the journal, were analyzed. The high professionalism of the editorial staff and editing always attracted to the journal authors who were materials scientists and highly qualified workers of scientific research and teaching institutes, and workers in enterprises of various branches of industry. The popularity of the journal is demonstrated by the fact that it is subscribed to in all regions of Russia, nearby and distant countries, and an English version of the journal is subscribed to in many countries of the world. In No. 8 (2005) well-known scientists, i.e. members of the editorial staff, presented their scientific articles devoted to the MiTOM jubilee.
Currently the journal continues to develop, maintaining traditions laid down by its chief editors A. P. Gulyaev $(1960-1998)$ and B. A. Prusakov (1998 - 2008). The international authority of the journal is growing: it is indexed in the database of the scientific information institutes of various countries. The number of publications from specialists of other countries has increased: USA, Germany, Slovakia, China, India, Turkey, Iran, Mexico, Malaysia, etc. The quality of articles presented by Russian specialists has not decreased.

This issue of the journal is devoted to its good round date (two fives), i.e. 55 years. Within it we have decided not place statistical data and material analyzing the activity of the journal. Let us assume that the nature of the journal will be in the articles published below, written from the results of original scientific work by well-known materials scientists who an members of the editorial staff. 